\title{
Review: individual variables have low power to predict recidivism with sex offenders
}

\author{
Hanson RK, Bussière MT.Predicting relapse: a meta-analysis of sexual offender recidivism studies.J Consult Clin Psychol 1998 \\ Apr;66:348-62.
}

\section{Question}

What factors are related to sexual, non-sexual violent, and general (any) recidivism among sexual offenders?

\section{Data sources}

Studies were identified by searching PsycLIT and the National Criminal Justice Reference System using the key words sex(ual) offender, rape, rapist, child molester, pedophile, pedophilia, exhibitionist, exhibitionism, sexual assault, incest, voyeur, frotteur, indecent exposure, sexual deviant, paraphilia(c), predict, recidivism, recidivist, recidivate, reoffend, reoffense, relapse, and failure. Reference lists of identified articles were also scanned, and letters were sent to 32 established sexual offender researchers requesting unpublished articles or data.

\section{Study selection}

Studies were selected if they followed a sample of sex offenders; reported recidivism information for sexual offences, non-sexual violent offences, or any reoffences; and included sufficient statistical information to calculate the association between a relevant offender characteristic and recidivism.

\section{Data extraction}

Data were extracted on nature of offence, duration of follow up, predictor variables, and recidivism rate.

\section{Main results}

61 follow up studies involving 28972 sexual offenders (12 to $5000 /$ study) were included. The studies were done between 1943 and 1995, only 55\% of them were published. 3 main categories of predictor variables were examined: criminal lifestyle, sexual deviance, and psychological maladjustment. In addition, clinical presentation and treatment compliance were examined as recidivism predictors. The predictive accuracy of most of the variables was small (range $r=0.10$ to $r=0.20$ ). No variable was sufficiently related to recidivism to use alone as a recidivism predictor, although statistical risk prediction scales produced larger correlations $(r=0.42$ to $r=0.46)$. Sexual offenders who recidivated with non-sexual, violent crimes tended slightly (a) to be younger than non-recidivists (recidivism rate difference [RRD] 24\%, 95\% CI 21\% to $27 \%$ ), (b) to be of a minority race (RRD 23\%, CI 19\% to 27\%), (c) to have a history of delinquency as juveniles (RRD 22\%, CI 15\% to 29\%) and a history of violent offences as adults (RRD $21 \%$, CI $15 \%$ to $27 \%$ ), and (d) to have a history of committing rape (RRD 23\%, CI 20\% to $26 \%$ ). The variables that tended to differentiate sex offenders who recidivated with sexual crimes were (a) sexual interest in children (RRD 32\%, CI 29\% to 35\%), (b) deviant sexual preference (RRD 22\%, CI $16 \%$ to 30\%) and (c) diagnosis of a severe psychological disorder (RRD 25\%, CI 10\% to 40\%). Finally, when no distinction in type of recidivism is made, recidivists tended to (a) have a delinquency history as juveniles (RRD $28 \%$, CI $22 \%$ to $34 \%$ ), (b) have a criminal history as adults (corrections admissions RRD 25\%, CI 19\% to 32\%; previous offences RRD 23\%, CI 21\% to 25\%), (c) have been diagnosed with a personality disorder (RRD 21\%, CI 9\% to 33\%), and (d) have failed to complete treatment (RRD 20\%, CI 13\% to 27\%).

\section{Conclusions}

Sexual recidivism is best predicted by measures of sexual deviancy, whereas non-sexual recidivism is predicted by general criminal history. No single variable is sufficiently predictive for use on its own, but risk prediction scales are more promising.

Source of funding: no external funding.

For correspondence: $\operatorname{Dr} R$ K Hanson, Corrections Research, Department of the Solicitor General of Canada, 340 Laurier Avenue West, Ottawa, Ontario K1A OP8, Canada. Fax +1 6139908295.

\section{Commentary}

Any study dealing with sex offender recidivism faces the almost incapacitating limitation that most criminal recidivism measures account for only a tiny proportion of the people who are actually committing more crimes. For example, it appears that $<10 \%$ of rape assaults were ever reported to the police during much of the historical period covered by this review by Hanson and Bussière. ${ }^{1}$ Conviction rates for sex offences are even more suspect; a careful study of 315 rapes reported in 1 geographic area found that only 15 resulted in conviction. ${ }^{2}$ Self reports of recidivism are equally worrisome for obvious reasons. As a result, we must always remember that most sex offender recidivism studies, including those in this review, do not tell us about all offenders who continue to commit crimes, but only about the small percentage of those who get caught again. This crucial fact undoubtedly makes it difficult to find substantial associations between predictor variables and reoffending. This fact also clouds the interpretation of even weak associations that might be found when trying to predict sex offender recidivism. For example, if a study finds, as this review does, that sex offenders whose victims were strangers tend to be slightly more likely to reoffend than offenders whose victims were acquaintances, it is quite possible that the result is an artifact of sexual crimes against strangers being more frequently reported than sexual crimes against acquaintances. Indeed, as hard as it is for researchers to admit, the gross underreporting of sex crimes makes clinically useful research on recidivism an elusive undertaking.

In addition to analysing recidivism prediction, this review calculated mean recidivism rates across 61 studies. Readers should be cautioned that most of the 61 studies used inadequate methods for calculating recidivism rates. ${ }^{3}$ Furthermore, averaging recidivism rates across studies whose follow up rates vary (in this case, from 6 months to 23 years) does not produce meaningful results. ${ }^{4}$

Lita Furby, MA, PhD Oregon State University Eugene, Oregon, USA

1 Russell DE. The prevalence and incidence of forcible rape and attempted rape of females. Victimology 1982;7:81-93.

2 Chappell DT, James J. Victim selection and apprehension from the rapist's perspective: a preliminary
investigation. Paper presented at the 2nd International Symposium on Victimology, Boston, national

3 Soothill KL, Gibbens TC. Recidivism of sexual offenders: a reappraisal. Br J Criminology 1978: 18:267-76.

4 Furby L, Weinrott MR, Blackshaw L. Sex offender recidivism: a review. Psychol Bull 1989;105:3-30. 